\title{
Current Status of High-n Immersion Lithography Development
}

\author{
Harry Sewell ${ }^{(1)}$, Jan Mulkens ${ }^{(2)}$, Christian Wagner ${ }^{(2)}$, Diane McCafferty ${ }^{(1)}$, \\ Louis Markoya ${ }^{(1)}$, Matthew Lipson ${ }^{(1)}$, and Nandasiri Samarakone ${ }^{(3)}$.

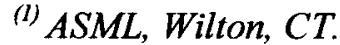 \\ (2) ASML, Veldhoven, Netherlands. \\ (3) ASML, Sunnyvale, CA.
}

\begin{abstract}
A feasibility study is being conducted on the subject of extending the resolution capability of immersion lithography exposure systems with high-n fluids to $35 \mathrm{~nm}$ and below. Fluids, for evaluation, are available from chemical vendor companies such as DuPont, Mitsui, and JSR. The new fluids have a refractive index of approximately 1.65. This makes it possible to design optics with a numerical aperture of 1.55 , which is a $17 \%$ extension on the highest numerical aperture possible with water-based immersion lithography.

The feasibility study has examined all the key factors associated with the possible introduction of high index immersion lithography. These aspects include: fluid handling challenges; UV exposure impact on fluid performance; fluid recycling to mitigate the effects of UV exposure; fluid interaction with resist; and the mechanisms involved in the generation of stains and imaging defects. Imaging tests using interference printing to define profiles in resist at $29 \mathrm{~nm} \mathrm{L/S}$ are reported.

To complete the analysis, the progress in enabling developments such as final lens element optical materials is reported, and the potential position for the technology in the lithography roadmap is discussed.
\end{abstract}

Keywords: Immersion lithography; 193nm lithography; High-n Immersion fluids; Immersion defects.

\section{Introduction}

The resolving powers of current optical exposure tools have reached $1.35 \mathrm{NA}$ using water based immersion-fluid technology. High-n immersion technology may have the capability to extend optical lithography beyond 1.35NA. There is a window for this technology before production EUV lithography becomes available. High-n immersion lithography may potentially be initially used with single step patterning technology and, subsequently, with double patterning lithography for $32 \mathrm{~nm}, 22 \mathrm{~nm}$ and $16 \mathrm{~nm}$ nodes.

Currently, the highest NA lens that is available is 1.35 for water-based immersion.
Figure 1 indicates the development options for the optical design. The options highlighted are for numerical apertures of 1.45 and 1.55 using $2^{\text {nd }}$-generation immersion fluid, and 1.65 using a $3^{\text {rd }}$-generation immersion fluid. The $3^{\text {rd }}$-generation immersion fluids $(n>1.8)$ are currently subject to significant development effort and candidate fluids are being identified. These $3^{\text {rd }}$-generation fluids are not yet available, but $2^{\text {nd }}$-generation fluids are available.

To answer the questions associated with high-n immersion lithography, we embarked on a feasibility study, which evaluated the key technical challenges. 


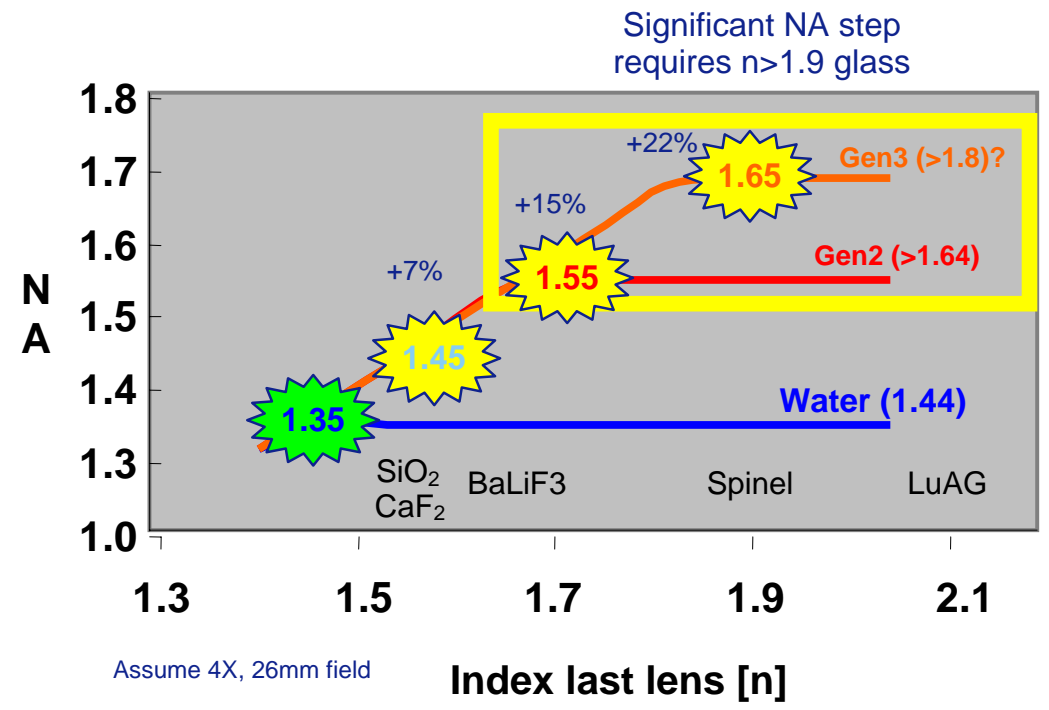

Figure 1. Optical Design Options for Immersion Lithography Systems

\begin{tabular}{|l|c|}
\cline { 2 - 2 } \multicolumn{1}{c|}{} & \multicolumn{1}{c|}{ Spec } \\
\hline $\begin{array}{l}\text { refractive } \\
\text { index }\end{array}$ & $>1.64$ \\
\hline $\begin{array}{l}\text { Absorption } \\
\mathrm{A}_{10}\end{array}$ & $<0.1 / \mathrm{cm}$ \\
\hline dn/dT & $\sim 500 \mathrm{ppm} / \mathrm{K}$ \\
\hline viscosity & $<0.003 \mathrm{~Pa} \mathrm{~s}$ \\
\hline $\begin{array}{l}\text { Surface } \\
\text { tension }\end{array}$ & $\sim 70 \mathrm{mN} / \mathrm{cm}$ \\
\hline
\end{tabular}

\begin{tabular}{|c|c|c|c|c|c|c|c|}
\hline A & B & C & D & E & F & G & Water \\
\hline 1.64 & 1.64 & 1.66 & 1.64 & 1.65 & 1.64 & 1.62 & 1.44 \\
\hline 0.116 & 0.036 & 0.060 & 0.067 & 0.032 & 0.020 & 0.850 & 0.032 \\
\hline-570 & -550 & -560 & -570 & & -565 & $?$ & 100 \\
\hline 0.0024 & 0.0033 & 0.0026 & 0.002 & 0.003 & 0.002 & $<0.005$ & 0.001 \\
\hline 30 & 32 & 30 & -30 & -30 & $\sim 30$ & & 72 \\
\hline
\end{tabular}

Figure 2. Data of available high-n immersion fluids

\section{Feasibility Study}

For the high-n immersion lithography option, the key questions for the feasibility study are grouped in a number of study areas: High-n fluid availability and properties? Fluid handling on the exposure system? Optics design and optical materials? These areas are reviewed.

\subsection{High-n immersion fluid availability and properties}

\subsubsection{Fluid Availability}

Second-generation immersion-fluids have been available from multiple suppliers for about two years ${ }^{(1,2 \text {, and } 3)}$. Figure 2 surveys the data. The availability of fluid samples has allowed the experimental addressing of questions about fluid contamination and degradation plus the development of fluid recycling technology.

In general, $2^{\text {nd }}$-generation fluids have a refractive index of $1.64+/-0.1$ (specification $n>1.64$ ) and absorption values at $193 \mathrm{~nm}$ wavelength of $\mathrm{A}_{10}<0.04$ (specification <0.10). Viscosity values are close to the specification value of $<0.003$ Pas. The fluids look very promising. The major 
concerns are the $\mathrm{dn} / \mathrm{dT}(-550 \mathrm{ppm} / \mathrm{K})$ and the robustness of the fluid when irradiated with 193nm illumination.

Temperature coefficient is an issue because small changes in the fluid's refractive index will induce significant aberrations to the imaging of the optical system. Image quality calculations show that the relatively high temperature coefficient of the fluids will require that the fluid temperature be controlled, and stabilized, to $<1 \mathrm{mK}$ for a 1.55NA optics, when using $2^{\text {nd }}$-generation immersion fluids. The feasibility study is aiming to demonstrate how well temperature of the fluid can be controlled. Currently no accurate measurements exist. This control is thought to be possible, though difficult, to achieve.

The feasibility study identified a number of causes of temperature changes that must be controlled. The major ones are the evaporation of the fluid off the wafer/resist surface and the energy delivered by the imaging dose to the fluid. Compared to water, the new $2^{\text {nd }}$-generation fluids have an 8 to 15 times lower evaporation rate. To a large degree, the lower evaporation rate of the fluid compensates for its higher thermal sensitivity.

The heating effects of the exposing energy drives two specifications: the fluid absorption specification $\mathrm{A}_{10}$ and the fluid flow rate through the showerhead. High flow rates move heated fluid quickly out of the optical path and limit the temperature deviation. High fluid absorption values drive up the exposure heat load.

\subsubsection{Fluid containment}

Showerhead design for the new fluids has progressed. A test stand is being used to develop new fluid showerhead and wafer system designs. Data graphed in Figure 3 compares the effect of scan speed on fluid containment with that of water. The contact angle data is plotted for the trailing meniscus edge and for scan speed. Compared with water, the current $2^{\text {nd }}$-generation fluids are very difficult to contain completely.

Typically, scanning speeds of $>0.5$ $\mathrm{m} / \mathrm{s}$ leave fluid behind on the resist-coated wafer. The graph shows the trailing edge contact angle. For water, the contact angle of the trailing edge remains finite for scan speeds up to $900 \mathrm{~mm} / \mathrm{sec}$, hence the water is contained. For high-n fluids, the contact angle of the trailing edge collapses to zero for scan speeds above $100 \mathrm{~mm} / \mathrm{sec}$, hence the fluid escapes and is not contained. It is the effect of the fluids viscosity and surface tension.

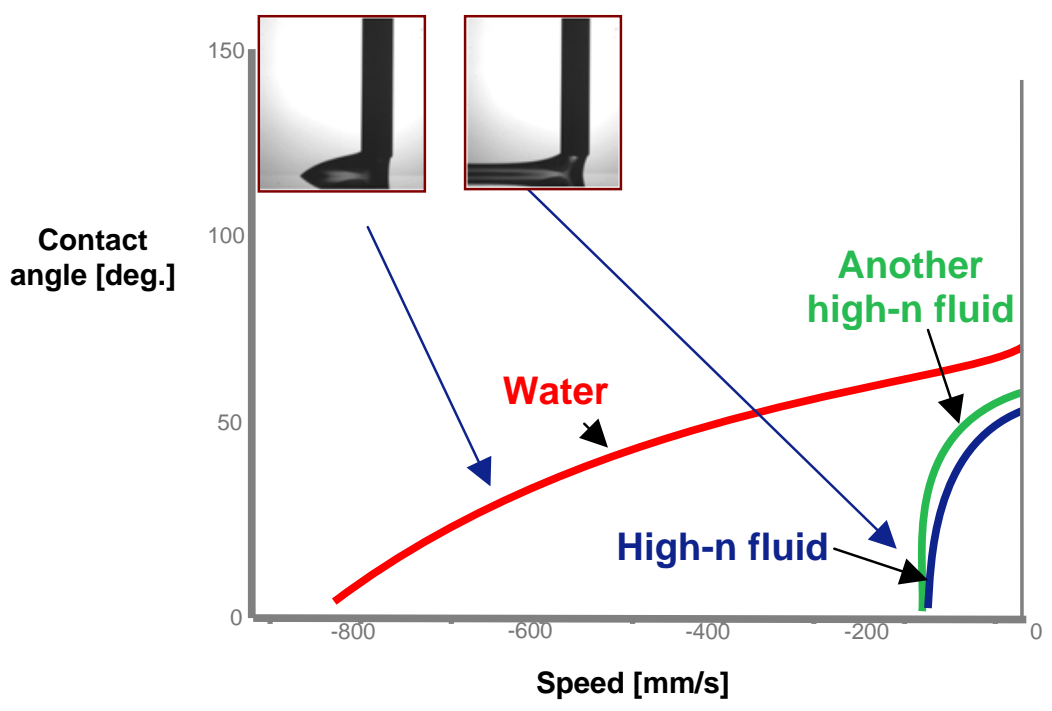

Figure 3. Scan speed effect on fluid containment. 
The scanning test results imply that full containment of high-n immersion fluids may not be possible at the high scan speeds used in lithography and therefore significant redesign of the fluid containment assembly will be required.

Typically, fluid is left on a wafer to dry. The residual high-n immersion fluid evaporates very slowly, $>5$ minutes. Initially, the resist is completely wetted by the fluid, but in less than a minute, the fluid film begins to break up into droplet patterns. After 3 minutes most of the droplets have evaporated. This drying time is very dependant upon the specific high-n fluid being tested.

It is assumed that the wafer surface will remain wet with the high-n fluid and that the drying effects of fluid films are important. Figure 4 shows a typical drying sequence. It follows that the resist process must be insensitive to the fluid and that these drying droplets must not leave defects. The issue of fluid drying on resist is being studied.

\subsection{Can we use the fluid?}

Feasibility study testing of fluid drying on wafers has taken two forms: Simple droplet drying tests on bare silicon and resist coated silicon wafers; CD Uniformity test wafers soak tests with fluid puddles.

\subsubsection{Droplet drying tests}

In Figure 5, droplet drying test results are shown. Several fluids from several suppliers were tested. It was observed that the fluids were not yet clean enough for high volume semiconductor manufacturing. Particulate defects, tarry skin residues, and crystalline deposits were all visible. The source of each of these problems was sought. Leaching of plasticizer from tubing was suspected ${ }^{(4)}$, as was interaction with container materials and syringes. Particulates were coming from fluid recycling columns. The sources of all of these residues have been found and removed by the fluid vendors. Major progress has been made. Figure 6 shows the latest results from droplet drying tests, essentially clear of defects.

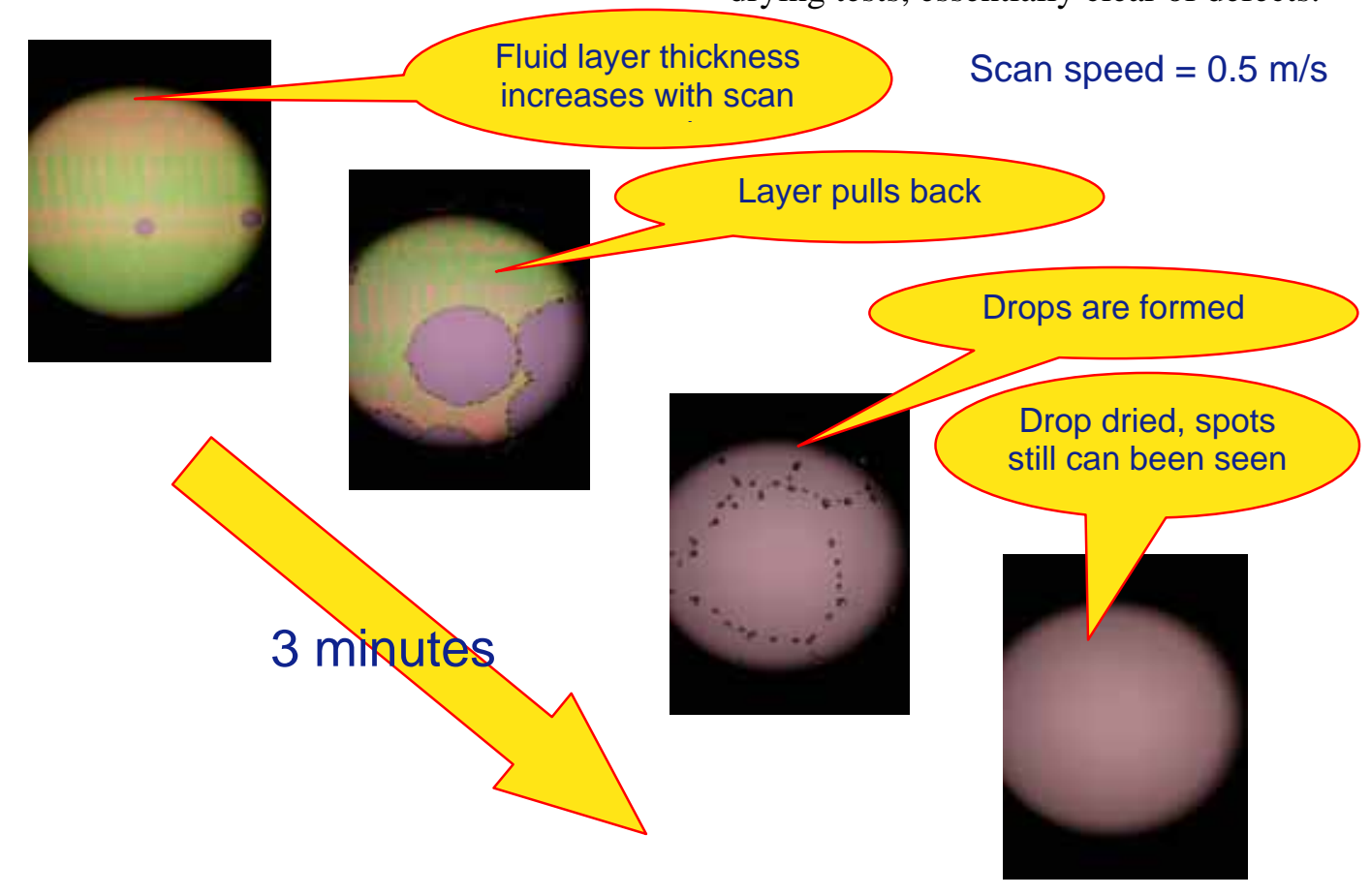

Figure 4. Typical high-n fluid drying sequence on a wafer. 


\section{December 2006}

- Particulate contamination

- "Skin" residues
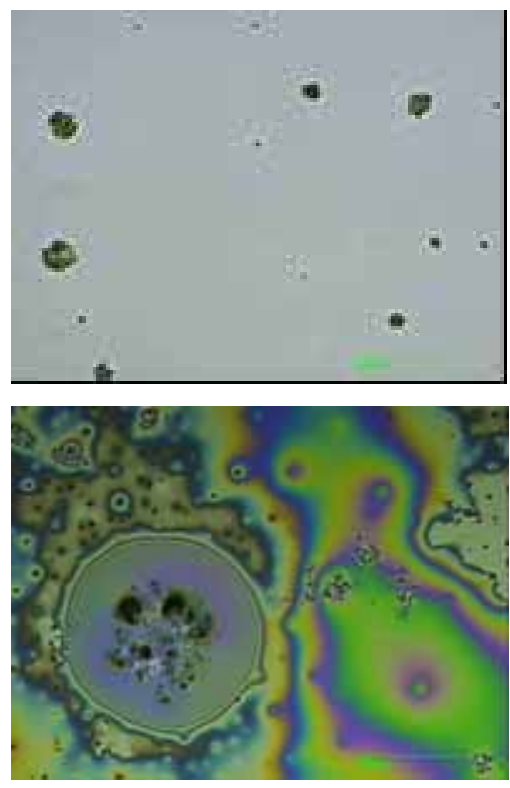

\section{February 2007}

•: Low residue

- "skin" not apparent

- Substantially reduced particles

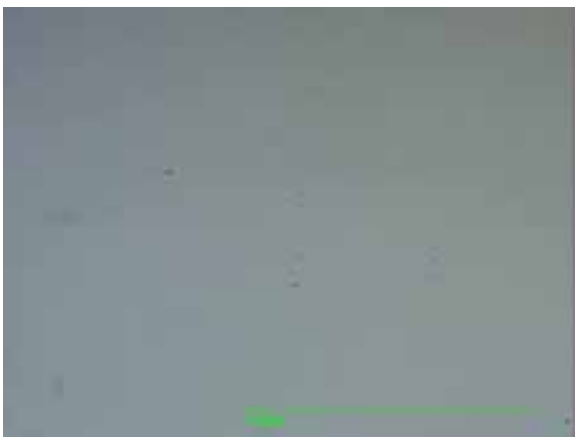

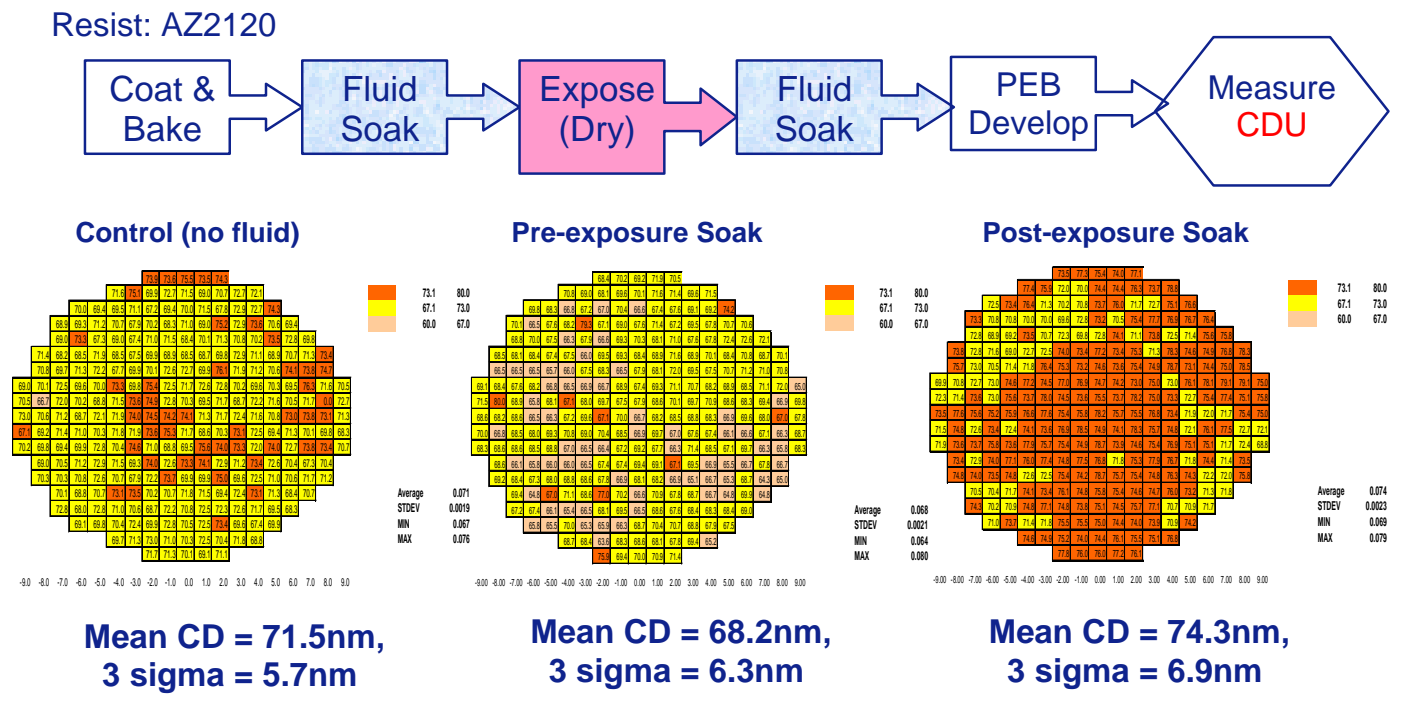

Figure 7. CD uniformity tests. Impact of fluid soaking on resist imaging 


\subsubsection{Critical dimension (CD) uniformity tests \\ CD uniformity test results are} promising. Figure 7 shows typical results. A slight change in the mean CD $(<2 \mathrm{~nm})$ for $70 \mathrm{~nm}$ lines is normally observed. Experiments indicate that results depend both on immersion fluid type and on resist type. The results also indicate that the effect of the fluid on the resist differs between before and after exposure application. The application of fluid before the resist exposure tends to decrease the measured CD after development, while the application of fluid after resist exposure tends to increase CD after development.

The application of fluid both before and after exposure (similar to an exposure tool) tends to leave a slightly increased CD $(1 \mathrm{~nm})$ over a dry control wafer. This is a similar value to that measured using DI water. Experiments on drying time versus CD uniformity indicate that the fluids must be adequately spin-dried before post-exposure bake.
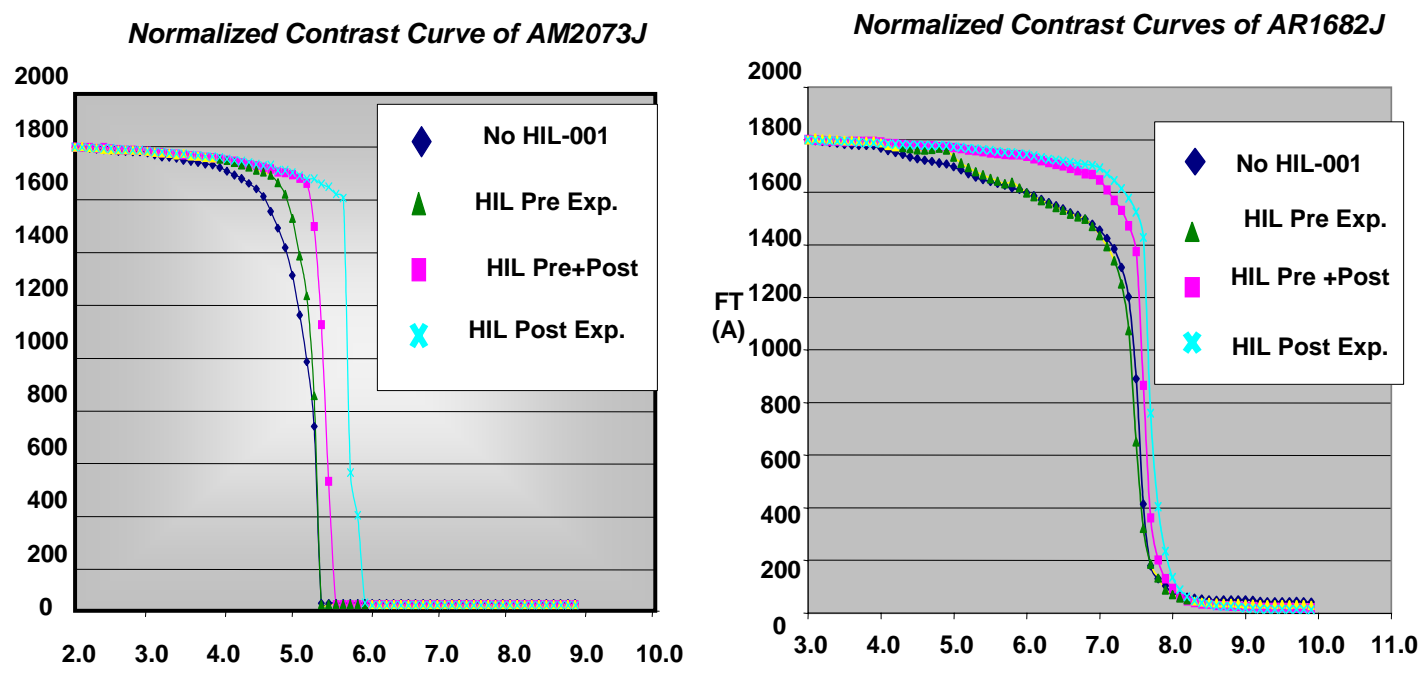

Figure 8. Contrast curve effects for pre- and post-exposure HIL-001 soak test on JSA resits

It is also observed that these results are dependant greatly on the actual resist system and fluid combination. Good results were obtained with TOK6111 and with AZ2120.
Joint testing with JSR on different JSR resists was carried out. Results of contrast curves which were generated are shown in Figure 8. They show the different effect on the resist contrast of the pre- and the post-exposure fluid application. Contrast curve testing is attractive because the results are independent of focus and exposure uniformity effects.

The testing of high-n fluid in conjunction with resist coated wafers is showing very promising results, especially compared to water. The feasibility study next looked at the challenge of handling the fluid on the exposure tool.

\subsection{Fluid handling on the exposure system.}

An exposure system consists of a lens, a fluid-containment system (showerhead assembly) and a fluid-handling system.

The fluid handling concept now being explored is diagrammatically shown in block diagram form in Figure 9. It consists of a fluid supply with a fluid purification (recycling) unit (being supplied by the fluid vendor). 


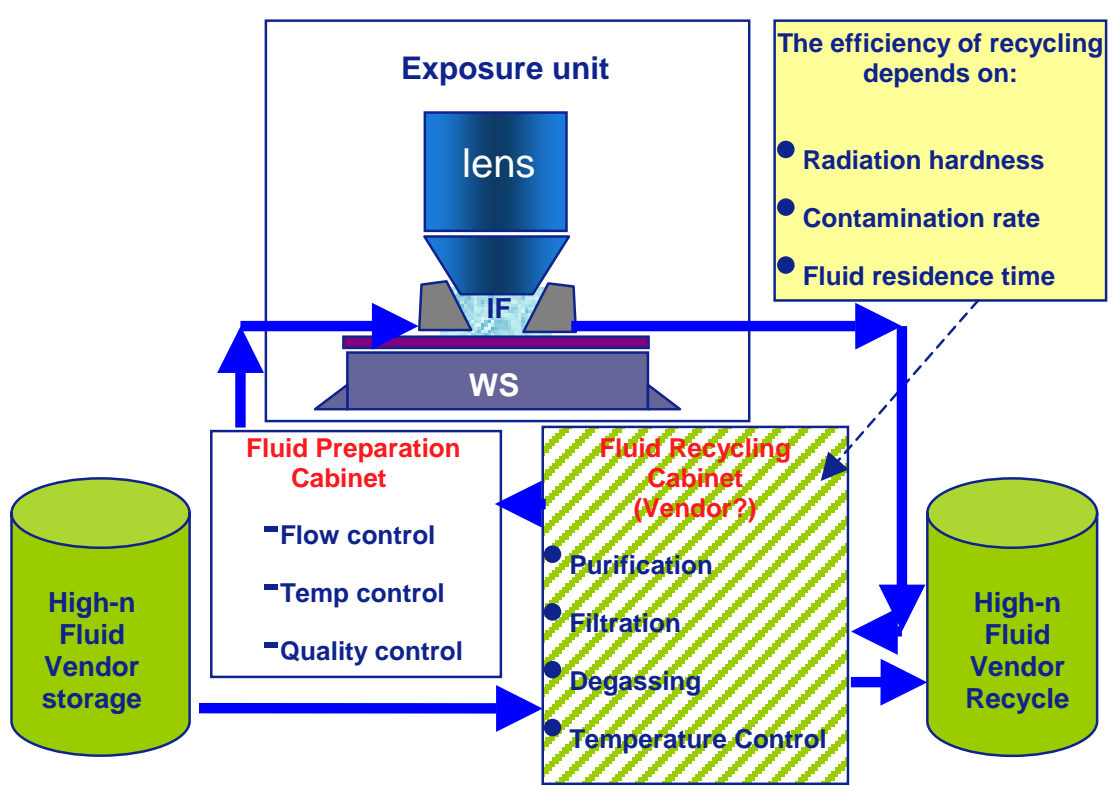

Figure 9. Fluid handling system (fluid vendor sub-system)

The fluid supply unit interfaces with the exposure tool. It has storage units with fully integrated pumping, filtration, and fluid reconditioning sub-systems. The exposure tool has sub-systems to pump, control temperature, recycle, filter, and monitor the fluid as it is used in wafer exposure sequences. The fluid is constantly recirculating through the tool's showerhead. Fluid is also circulated through the purification system to keep it within specific control limits. The role of the purification systems is to remove breakdown products that are the result of the photodecomposition of the fluid by the 193nm radiation. It is also required that any oxygen, which is a contaminant in the fluid, be removed because it reduces fluid transparency at $193 \mathrm{~nm}$ wavelength.

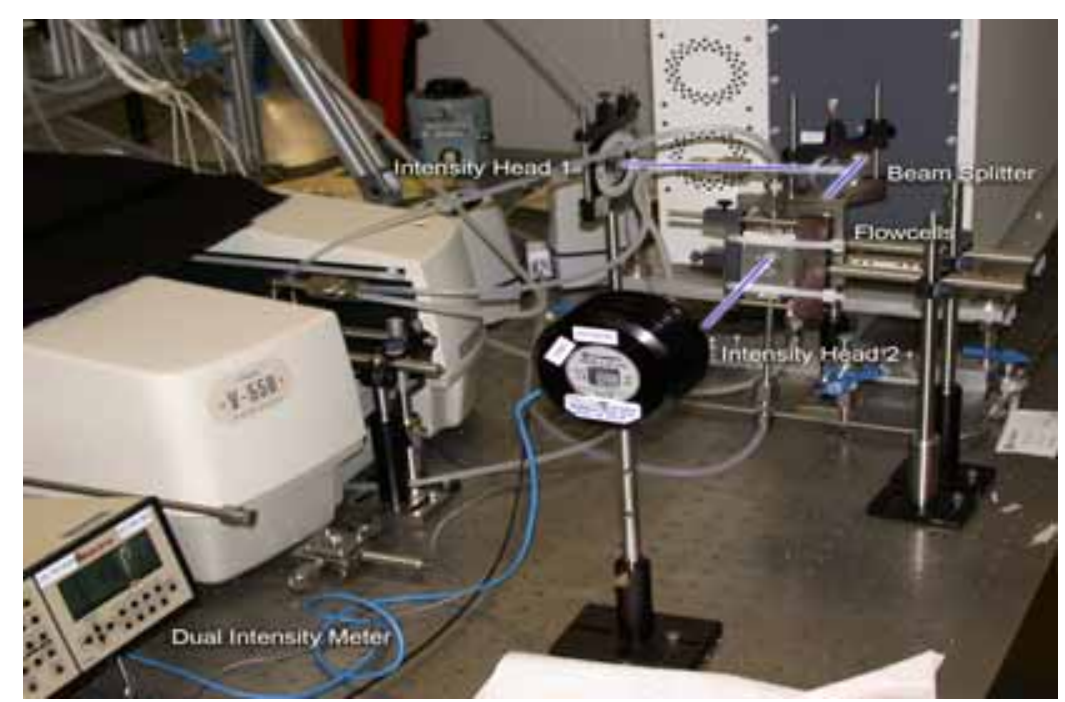

Figure 10. Fluid irradiation and absorption measurement test apparatus 


\subsubsection{UV hardness of high-n fluids}

Part of the feasibility study to evaluate high-n immersion fluids examined its UV hardness and how the fluid handling system on the exposure tool could deal with it. Fluid degradation and optics contamination were examined. Figure 10 shows the test apparatus used for the measuring of fluid absorption and for irradiating of the fluid in a flow cell with laser illumination.

The absorbance of the fluid is measured in a multiple path length metrology cell located in the spectrometer (Jasco V-550). Intensity head 1 measures the reference beam for monitoring beam energy from the laser. Intensity head 2 monitors the laser beam energy transmitting through the flow cell and hence any degradation in that energy transmittance.

Fluid samples are being supplied at regular intervals by vendors, particularly DuPont. Exposure to 193nm illumination degrades the fluid and increases absorption. Figure 11 and 12 shows typical experimental results for the UV irradiation of $2^{\text {nd }}$-generation fluids (DuPont IF132).
Fluid absorption at 193nm 658 ength is monitored using a speci 657 logy fluid cell. This metrology cell $\mathrm{h}$ three path lengths for the fluid so that by simple subtraction, the impact of the quartz windows on the cell transmission can be removed. An active recycle package supplied by the fluid vendor purifies the fluid during the irradiation cycle and reduces the fluid degradation rate significantly by removing breakdown radicals. Figure 11 indicates the place on the graph at which oxygen absorbed in the fluid is being removed. Also shown is the point at which the fluid recycle package is turned on. Once the absorption of the fluid has been stabilized and measured, the laser irradiation of the flow cell at $6.8 \mathrm{~mJ} / \mathrm{cm} 2$ at $100 \mathrm{~Hz}$ is turned on and the fluid degradation rate of the transmission for the metrology cell recorded. In this test, 10,800 secs is equivalent to $24 \mathrm{hrs}$ on a Twinscan system. Fluid absorption degraded by $0.013\left(\mathrm{~A}_{10} / \mathrm{cm}\right)$. The fluid degradation rate with UV irradiation shown in Figure 12.

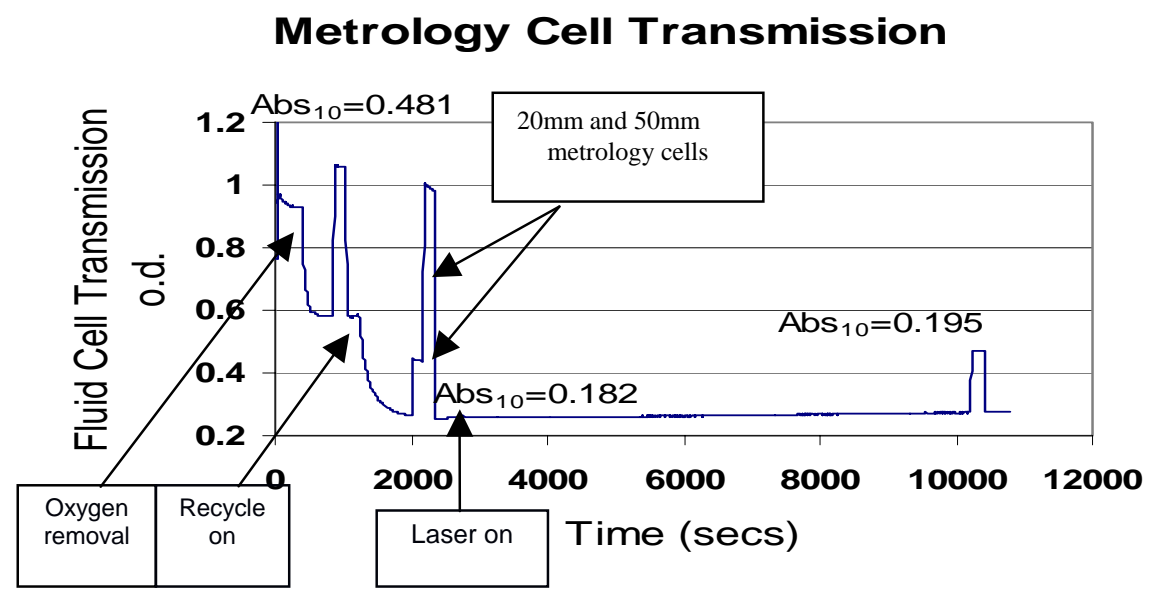

Figure 11. Fluid irradiation results measured in the metrology cells 
A typical transmission results for the irradiated flow cell is shown in Figure 13. The results show the darkening effect of the UV

Window contamination has been of particular concern in the feasibility study. Contamination rate has been measured. It is found that used fluid contaminates the window at approximately the same rate as fresh, new, highly transparent fluid. Currently, for the conditions used in the reported experiment, the transmission loss due to window contamination can be as low as $1 \%$ for the equivalent of $24 \mathrm{hrs}$ run on a Twinscan system. irradiation on the flow cell as residues build up on the cell windows and the fluid transparency degrades.

Experiments on the cleaning of windows have been conducted. Cleaning processes that are effective in removing residues from irradiation have been developed. Nevertheless, optics contamination has been identified as a major issue and is being fully characterized so that rates can be reduced. Assessments on the ability to handle high-n fluid on the exposure system are optimistic, with the exception of the concern over the

\section{Fluid Transmission Degradation against Laser Energy}

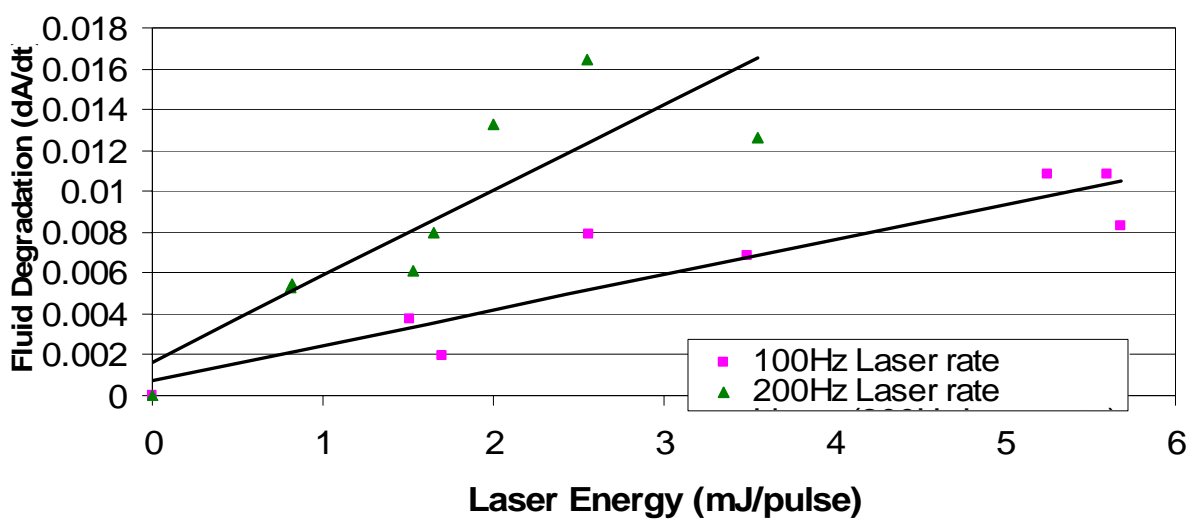

Figure 12. Fluid degradation rate against Laser Energy

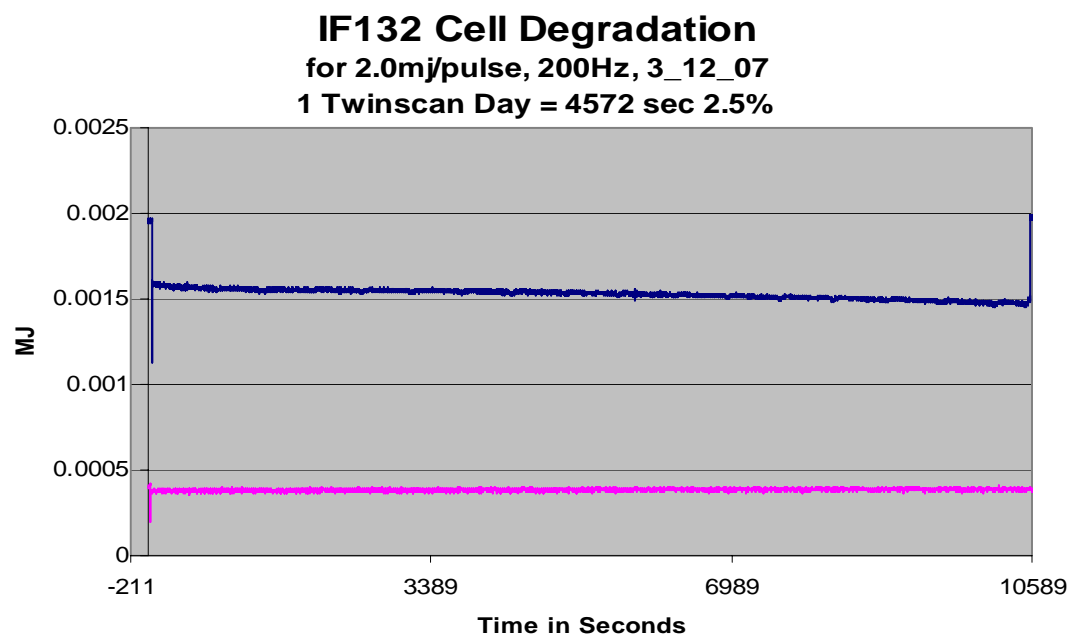

Figure 13. Fluid flow cell darkening 
issue of final lens element cleaning. A bigger concern though, is over the optics design and more importantly the material for the final lens element.

\subsection{Optics design and optics materials}

The application of $2^{\text {nd }}$-generation fluids to optical lithography is limited by materials in the thin film stack between the wafer and the final lens element because:

$$
\begin{gathered}
\text { Numerical Aperture (NA) }=\mathbf{n}_{1} \cdot \sin \left(\theta_{1}\right)= \\
\mathbf{n}_{2} \cdot \sin \left(\theta_{2}\right)=\mathbf{n}_{3} \cdot \sin \left(\theta_{3}\right)=\ldots \ldots \ldots \ldots
\end{gathered}
$$

Where $n 1, n 2, n 3, \ldots .$. are the refractive indices of the various material layers in the planar film stack.

For the water-based system, the limitation in numerical aperture is the immersion fluid (water) $n=1.44$. $\operatorname{Sin} \theta$ for the aperture defining rays cannot physically be 1.0. A factor of 0.9 is possible. This gives a maximum NA of 1.35 , limited by the water. Using the same calculation on a $2^{\text {nd }}$ generation fluid $(n=1.65)$ gives a maximum NA of 1.55, as long as the fluid is the limiting refractive index in the thin-film stack. Currently, it is not. Quartz or calcium fluoride optical material in the final lens element have $\mathrm{n}=1.55$ at $193 \mathrm{~nm}$, this limits the possible NA to 1.40 , even with $2^{\text {nd }}$-generation immersion fluids, unless the refractive index of the optical material in the final lens element is increased.

One possible solution is the use of BaLiF3 with $n=1.65$ for the final lens element, this allows the numerical aperture of the optics to be increased to the highlighted value of 1.45 (see Figure 1). Increasing the numerical aperture from the current 1.35 to 1.45 is only a $7 \%$ increase and is not considered to be enough to warrant the extensive development effort that would be required to bring on line the technology of a new class of immersion fluids and optical material. Attention is therefore focused on finding new final lens element optical materials that have refractive indices of $>1.65$. Figure 13 indicates the current status.

Substantial progress has been made in this area by companies such as Schott. Schott reports $^{(5,6)}$ development work on materials such as LuAG, and sapphire. LuAG has a refractive index of 2.1 and with low optical scatter. The concern with LuAG is optical absorption and birefringence (both intrinsic and stress). For LuAG, the main parameter under focus is the optical absorption value $A_{10}$. This has been reduced to $<0.2 / \mathrm{cm}$ and the target value is $<0.003 / \mathrm{cm}$. This must be improved by a factor of 60 , this is a challenge, and has a long way to go. The outlook for significant further reduction, though, is good. The absorption level depends on levels of impurities. Impurity reduction is expected in areas such as the furnace, the crucible, and the starting materials. The preparation of proof samples is under way. Intrinsic birefringence for LuAG is measured at $+30 \mathrm{~nm} / \mathrm{cm}$. While this is higher than is desirable $(<10 \mathrm{~nm} / \mathrm{cm})$ it is possible to compensate for it. Stress birefringence is currently $<5 \mathrm{~nm} / \mathrm{cm}$, and the target is $<1 \mathrm{~nm} / \mathrm{cm}$. There is optimism that the stress birefringence and homogeneity targets can be achieved with improved thermal control during crystal growing.

For optical material, the developmental progress must be maintained. This is the most critical factor for high-n immersion technology. An update on LuAG results is expected in June 2007.

If viable optical material becomes available, such as LuAG, or Spinel, the design of the optics with NA values of 1.55 is not expected to be a major problem. There is confidence that current designs ${ }^{(7,8)}$ used for 1.35NA optics can be extended at least up to $1.56 \mathrm{NA}$.

\subsection{Imaging}

Imaging is a key component of the feasibility study. Resist cross-sections of $100 \mathrm{~nm}$ lines taken from CD uniformity testing is shown in Figure 14. There is essentially no significant difference in resist profile between the soaked resist imaging and the dry imaging. 


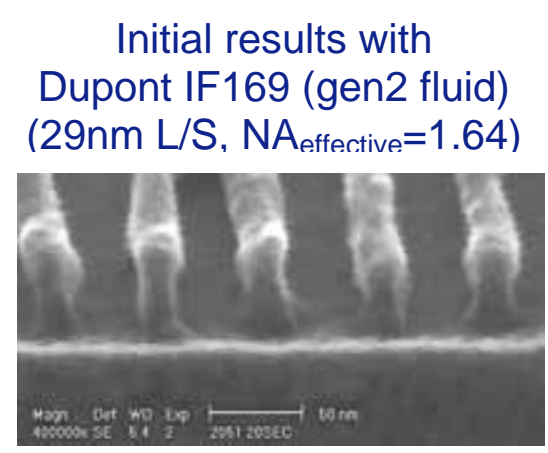

LS using an interference set-up 85 nm ARC-29A, 50 nm PARIM850 resist

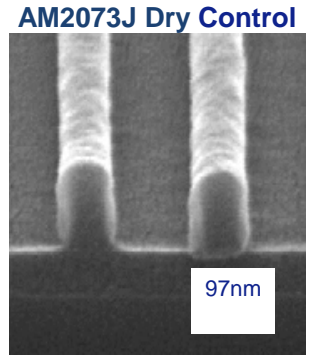

AM2073J Exposed To HIL 001

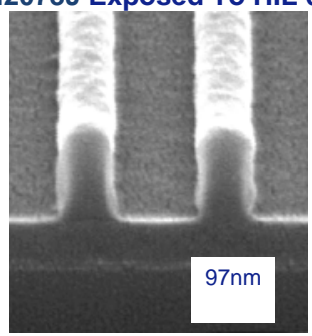

Figure 14. Imaging results with second-generation fluid: $\mathrm{CD}$ uniformity resist profiles for $100 \mathrm{~nm}$ lines; and 29nm L/S using an interference printer (NA effective is 1.64)

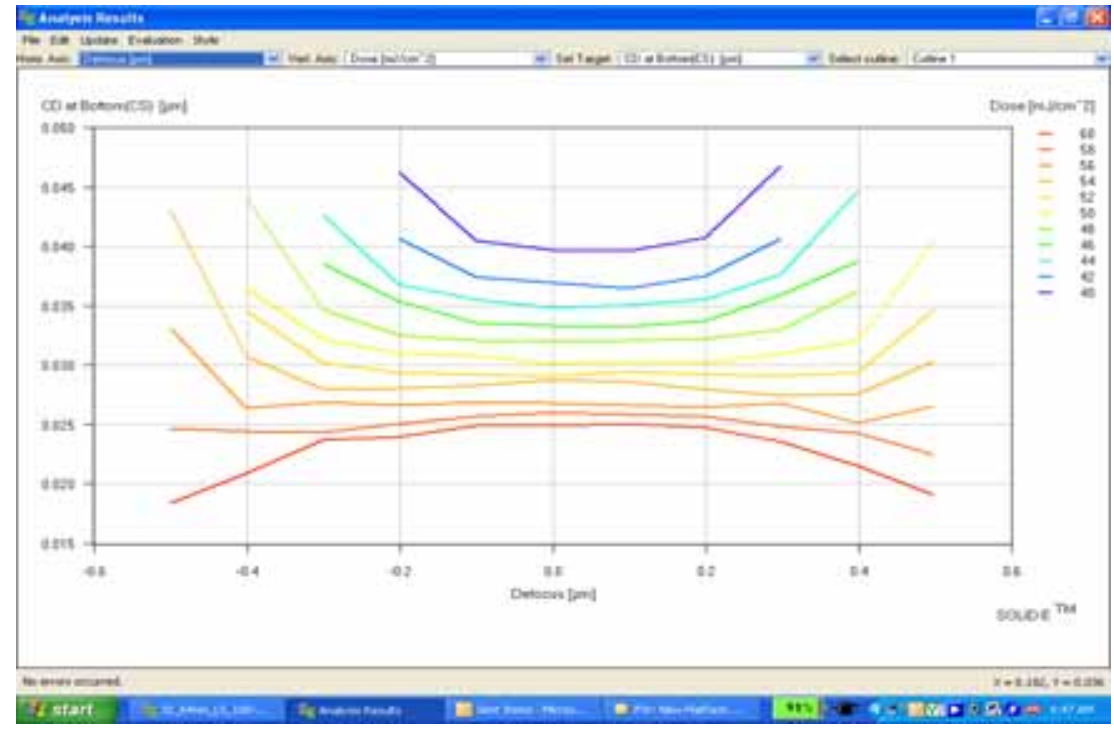

Figure 15. Depth of focus simulations for 32nm L/S using aggressive low-k techniques 
Tests using an interference imaging test stand $^{(9,10)}$ demonstrate that $29 \mathrm{~nm} \mathrm{L/S}$ printing is available with $2^{\text {nd }}$-generation fluids on currently available chemically amplified resists (effective numerical aperture was 1.64 , using fluid with $n=1.65$ ). Figure 14 shows typical $29 \mathrm{~nm} \mathrm{~L} / \mathrm{S}$ results. The resists do have line edge roughness (LER), but this is generated by the chemistry of chemical amplification, rather than by any interaction with the $2^{\text {nd }}$-generation immersion fluid. Improvements in the engineering of the resist are expected to reduce line edge roughness.

The interferometer test stand is also being used in the assessment of thirdgeneration immersion fluid candidates. Path lengths in the fluid have been shortened to accommodate higher fluid absorption. To date, no candidate fluids have been available with measured refractive index that exceeds 1.73, and even these fluids are currently too absorbing to test. Progress on $3^{\text {rd }}$-generation fluids and on the development of high-n resists ${ }^{(11)}$, which will be required to gain the full potential of a $3^{\text {rd }}$-generation fluid, is slow but ongoing. The feasibility study is highlighting the challenging issue of engineering a $3^{\text {rd }}$-generation immersion fluid.

\subsection{Imaging simulations}

Simulations of the performance of a $1.55 \mathrm{NA}$ imaging system are shown in figure 15. They indicate that a good process window is possible for $32 \mathrm{~nm} \mathrm{L/S} \mathrm{imaging} \mathrm{using}$ aggressive low-k image enhancement techniques. Depth of focus of over 0.8um is possible with an exposure latitude, at best focus, of $20 \%$. Aggressive polarized dipole illumination is used with special attenuated phase shift masking.

\section{Summary and Conclusions}

The feasibility study is producing a wide range of results. Many areas of technical challenges are deemed to be feasible; some are obviously more feasible than others. Results indicate that most of the challenges can be addressed and overcome. Three areas that could currently represent showstoppers: availability of optical-quality high-n final lens element material; optical surface contamination rate from the UV irradiation effects on the immersion fluid; the lack of availability of $3^{\text {rd }}$-generation immersion fluid (this limits the extendibility of the technology). All three of these areas are being worked on and could become feasible. High refractive index optical material proof samples may be available within the next few months. Experimentation with optical surface contamination mitigation is ongoing. The results in all areas are encouraging enough to continue the feasibility study. If these challenges are overcome then high-n immersion optical lithography could become viable.

\subsection{Outlook}

There is an opportunity for $2^{\text {nd }}-$ generation immersion at $34 \mathrm{~nm}$ half pitch. Second-generation fluid can extend single exposure immersion lithography toward $32 \mathrm{~nm}$ node. In the longer term, this high-n immersion technology may allow the extension of double processing lithography to past the $22 \mathrm{~nm}$ node. High-n immersion lithography can become an extender technology for double patterning. The window of opportunity is between the availability of new high-n final lens element material and the onset of production EUV lithography. It is expected that the primary application would be for the Logic sector.

\section{Acknowledgements}

The authors thank the following members of the material and fluid suppliers for their support in the testing: Roger French and John Schmieg of DuPont; Katsuhiko Hieda, Bill Peterson, Zhi Liu, and Mark Slezak of JSR; and Lutz Pathier, and Konrad Knapp of Schott.

We also thank: Mark Riggs, Bob Pattacini, Matt Lipson, Jim Hunter, Paul Yick, David Witko, Joost Systma, Jos Benschop, Sjoerd Donders, Steve Hansen, Donis Flagello and Bill Arnold at ASML and Wilfried Clauss, Reiner Garreis and Winfried Kaiser at Zeiss. 


\section{References}

1. S.Peng, R.French, W.Qiu, R.Wheland, M.Yang, M.Lemon, M.Crawford, "secondgeneration fluids for $193 \mathrm{~nm}$ immersion lithography," SPIE Optical Microlithography XVIII, 2005, Vol. 5754.

2. R.H.French et.al. "High-index immersion lithography with second-generation immersion fluids to enable numerical apertures of 1.55 for cost effective $32 \mathrm{~nm}$ half pitches," SPIE Optical Microlithography XX, 2007, Vol. 6520.

3. T.Furukawa, T.Kishida, T.Miyamatsu, K.Kawaguchi, K.Yamada, T.Tominaga, M.Slezak, K.Hieda, "High-refractive index materials design for ArF immersion lithography," SPIE Advances in Resist Materials and Processing Technology XXIV, 2007, Vol.6519.

4. V.Liberman, S.Palmacci, D.Hardy, M.Rothschild, A.Grenville, "Controlled contamination studies in $193 \mathrm{~nm}$ immersion lithography," SPIE Optical Microlithography XVIII, 2005, Vol. 5754.

5. 3rd Immersion lithography symposium, 2006, Kyoto.

6. L.Parthier, G.Wehrhan, D.Keutel, K.Knapp,"Development status of high-index material LuAG for ArF hyper-NA immersion systems," SPIE Optical Microlithography XX, 2007, Vol. 6520.

7. R Garreis et.al., 3rd Immersion Symposium 2006, Kyoto

8. D.Flagello, S.Hansen, B.Geh, M.Totzeck, "Challenges with hyper-NA $(\mathrm{NA}>1.0)$ polarized light lithography for sub lambda/4 resolution," SPIE Optical Microlithography XVIII, 2005, Vol. 5754.

9. S.V.Postnikov, M.Ercken, P.Foubert, R.Gronheid, E.Hendrickx, C.Jehoul, B.Kim, F.van Roey, J.Versluijs, N.Vandenbroeck, P.Willems, "Experimental observations of high-index liquid interaction with resist," SPIE Advances in Resist Materials and Processing Technology XXIV, 2007, Vol.6519.

10. H.Sewell, D.McCafferty, L.Markoya, E.Hendrickx, J.Hermans, K.Ronse, " $32 \mathrm{~nm}$ node technology development using interference immersion lithography," $2^{\text {nd }}$ Immersion Symposium 2005, Brugges.

11. W.E.Conley, "The application of highrefractive index photoresist for 32-nm device level imaging," SPIE Advances in Resist Materials and Processing Technology XXIV, 2007, Vol.6519. 